\title{
Asthma exacerbations . 5: Assessment and management of severe asthma in adults in hospital
}

\author{
Sarah Aldington, Richard Beasley
}

Thorax 2007;62:447-458. doi: 10.1136/thx.2005.045203

It is difficult to understand why there is such a huge discrepancy between the management of severe asthma recommended by evidence-based guidelines and that observed in clinical practice. The recommendations are relatively straightforward and have been widely promoted both in guidelines and reviews. Specialist physicians need to be more proactive in their implementation of such guidelines through the use of locally derived protocols and assessment sheets, reinforced by audit. The common occurrence of severe asthma and its considerable burden to the community would support such an approach.

See end of article for authors' affiliations

Correspondence to: Professor Richard Beasley, Medical Research Institute of New Zealand, P O Box 10055, Wellington, New Zealand; richard.beasley@ mrinz.ac.nz

Received 4 November 2005 Accepted

14 September 2006
O ver the last two decades, British guidelines on the management of asthma have provided evidence-based recommendations for the assessment and management of severe asthma in hospitals. ${ }^{1-3}$ Practical assessment and management algorithms have been provided, supported by clear advice regarding their implementation. Despite their availability and widespread promotion, repeated audits have indicated that there is a major discrepancy between the standard of current medical management of severe asthma in hospitals and that recommended in the guidelines. ${ }^{4-6}$ Common problems include inadequate assessment and recognition of severity, confusion over the use and interpretation of investigations, insufficient use of systemic steroids, over-reliance on bronchodilators, delayed specialist or intensivist referral and poor follow-up arrangements including communication with the general practitioner (GP) (table 1).

Recognition of these problems provides a good basis for determining priorities for the hospital care of patients with severe asthma (table 2). In this review we focus on these issues and the clinical approaches that might be used to improve the management of severe asthma in adults in hospital. We also highlight the use of assessment sheets and treatment protocols in the emergency department to illustrate how the guidelines can be implemented in a simple and practical manner. The review also raises issues of clinical uncertainty that need to be considered in updated versions of the guidelines and where further research is required.

\section{HISTORY}

A brief history can be obtained while the patient is being initially examined as part of the clinical assessment. The priority is to identify quickly the patient at increased risk of serious morbidity and mortality from asthma, and this can be achieved by asking a few questions to determine the background chronic asthma severity and the severity of the acute attack (table 3). Among the markers of an increased baseline risk of death that have been identified, a hospital admission in the previous 12 months is the most reliable and easily ascertained, with the occurrence of multiple hospital admissions for asthma signifying a greatly increased risk. ${ }^{7-9}$ The amount of $\beta$-agonist regularly used by the patient is also informative, based on epidemiological evidence that increasing use is associated with a progressively greater likelihood of a hospital admission and/or risk of death. ${ }^{10}$ For example, the Saskatchewan study reported that the risk of death increased markedly with the use of more than two $\beta$-agonist inhalers per month. ${ }^{10}$ The factor which identifies patients at greatest long-term risk of death is a previous life-threatening attack (ever), which is most easily documented by obtaining a history of a previous intensive care unit (ICU) admission for asthma. ${ }^{11}$

The amount of inhaled $\beta$-agonist self-administered during the exacerbation is a good marker of the severity of the acute attack and risk of a poor outcome. It also gives the attending doctor an indication of the likelihood of a response to further inhaled $\beta$-agonist treatment and requirement for systemic steroid treatment. In a study of adult patients admitted to hospital with severe asthma, ${ }^{12}$ about half had used at least 30 doses from their $\beta$ agonist inhaler in the $24 \mathrm{~h}$ before presentation and about 20\% had used over 60 doses. Most patients who had access to both an inhaler and nebuliser had used the nebuliser more than four times, as well as at least 20 doses of their inhaler during the $24 \mathrm{~h}$ period before admission. The likely poor response to further inhaled bronchodilator and the requirement for hospital admission and systemic steroid treatment could be predicted from such heavy prior $\beta$-agonist use.

For those patients who have monitored their peak flow during the attack, marked variability in peak flow with falls of $>50 \%$ from baseline is a marker of risk of sudden death. ${ }^{13}{ }^{14}$

The perceived speed of onset of the attack is also informative for recognising asthmatic patients

Abbreviations: CPAP, continuous positive airway pressure; $\mathrm{FEV}_{1}$, forced expiratory volume in $1 \mathrm{~s} ; \mathrm{HDU}$, high dependency unit; ICU, intensive care unit; NIPPV, noninvasive positive pressure ventilation; $\mathrm{PaO}_{2}, \mathrm{PaCO}_{2}$, arterial oxygen and carbon dioxide tension; PEF, peak expiratory flow; PVCD, paradoxical vocal cord dysfunction; $\mathrm{SpO}_{2}$, oxygen saturation 
Table 1 Hospital management of severe asthma: the problems

$\begin{array}{ll}\begin{array}{l}\text { Poor assessment with } \\ \text { resulting lack of recognition } \\ \text { of life-threatening asthma }\end{array} & \text { - } \begin{array}{l}\text { Inadequate history and examination } \\ \text { - } \text { Misuse and misinterpretation of arterial } \\ \text { blood gas measurements and chest }\end{array} \\ \begin{array}{ll}\text { Poor management with } \\ \text { raboptimal outcome }\end{array} & \begin{array}{l}\text { - Insufficient use of systemic steroids } \\ \text { - Over-reliance on inhaled bronchodilators }\end{array} \\ \text { Poor follow-up } & \text { - Misuse of intravenous bronchodilators } \\ & \text { - Long-term management not addressed } \\ & \text { - Poor communication with GP }\end{array}$

Table 2 Hospital management of severe asthma: the priorities

Practical assessment and management protocols Objective measurement of severity and identification of lifethreatening attack

Management determined by level of severity

Measurement of the response to treatment

Decision regarding admission/discharge; general/respiratory ward/high dependency unit (HDU)/intensive care unit (ICU) admission

Medical follow-up arranged and long-term management addressed prior to discharge

with "precipitate attacks" who are likely to present with more severe asthma but have a greater improvement with treatment. ${ }^{15-17}$ Overall precipitate attacks are uncommon, representing around one in eight presentations at the emergency department when defined as an onset of symptoms within $3 \mathrm{~h}$ of presentation. The more common presentation is that of a gradual deterioration over many days before a more rapid worsening just before presentation.

Additional history will be required, including markers of poor long-term control (such as nocturnal wakening) and precipitating factors, of which viral upper respiratory tract infections are most common. In cases of precipitate asthma, allergen exposure, use of non-steroidal anti-inflammatory drugs and psychological stress are important factors to consider. ${ }^{15-17}$ In addition to documentation of the routine medications (including compliance with inhaled corticosteroid therapy), consideration of other issues such as continuity of primary care, adverse behavioural or psychosocial problems and the presence of comorbid conditions is required. ${ }^{18}$

It is also informative to ask the patient to describe the sequence of events in the $24 \mathrm{~h}$ period before admission to establish if there was a significant delay in the recognition of the severity of the attack and whether earlier medical review

Table 3 Markers of risk of an adverse outcome in asthma

\begin{tabular}{ll}
\hline Baseline severity & Recent hospital admission \\
& Three or more regular medications \\
& Frequent "after hours" GP visits \\
& Psychosocial problems \\
& Previous ICU admission (ever) \\
Heavy use of $\beta_{2}$-agonist \\
Precipitate asthma \\
Marked ( $>50 \%$ ) reduction or variation in peak \\
flow
\end{tabular}

www.thoraxjnl.com should have occurred. This provides the opportunity to discuss "what should have happened in this attack" and recommend what steps might be taken to ensure a better outcome in the next attack. This advice may also serve as the basis for implementing a self-assessment and management plan prior to discharge.

Consideration should also be given to other disorders which may mimic or coexist with asthma. Particular consideration should be given to paradoxical vocal cord dysfunction (PVCD),${ }^{19}{ }^{20}$ which is normally recognised by patients attending the emergency room frequently with poorly reproducible lung function measurements and predominant wheezing during both expiration and inspiration originating from the larynx rather than the chest. Other distinctive features include a predominance in women, a background of psychological or psychiatric problems, and a lack of response to standard asthma management. Careful elicitation of symptoms and signs of PVCD at presentation may be helpful in its subsequent investigation, which is based on laryngoscopy and flow-volume loops. This is important not only because PVCD is amenable to treatment, but also because it can reduce the risk of substantial morbidity with intensive treatment including long-term oral corticosteroids.

\section{CLINICAL EXAMINATION}

The priority of the clinical examination is to confirm the diagnosis of asthma quickly and to assess its severity. The general appearance of the patient, including difficulty in talking, respiratory rate and heart rate form the basis of the clinical assessment of severity. ${ }^{21}{ }^{22}$ Increasing pulse rate has a close correlation with worsening asthma severity, and it is incorrect to assume that the tachycardia is due to $\beta$-agonist treatment. Studies of the response to high-dose $\beta$-agonist treatment in severe asthma have shown that the heart rate falls in association with the bronchodilator response. ${ }^{21} 23$

While it is generally well recognised that some patients may have a poor perception of the severity of their asthma, ${ }^{24}$ it is less well appreciated that such patients may also appear deceptively well, despite the presence of severe airflow obstruction. ${ }^{26}$ These factors contribute both to delay in seeking medical help by the patient and a tendency for the doctor not to appreciate the severity when the patient does present. This underlies the importance of lung function measurements in severe asthma, as well as eliciting other clinical signs such as the difficulty a patient may have in talking, ${ }^{21}$ blood pressure paradox, accessory muscle use and tracheal tug. In acute severe asthma, the marked hyperinflation and associated greater inspiratory muscle effort is responsible for the patient's perception that the difficulty in breathing is predominantly inspiratory rather than expiratory. ${ }^{27}$ The inspiratory muscle work may increase up to tenfold in patients with severe asthma in whom the $\mathrm{FEV}_{1}$ is $<50 \%$ of baseline. ${ }^{28}$

In clinical practice, signs such as a "quiet chest" and blood pressure paradox $(>15 \mathrm{~mm} \mathrm{Hg})$ should alert the doctor to the presence of a severe attack. ${ }^{21}{ }^{29}$ Although difficulties in their interpretation and wide observer variability have led to a reduced emphasis on their use, these clinical examination features are informative when carefully elicited, and clinicians are encouraged to develop and maintain these clinical examination skills. Other clinical signs which indicate lifethreatening asthma include patients assuming the upright position (or an inability to lie supine), cyanosis and sweating. ${ }^{21}$ Confusion or a reduced level of consciousness may be a premorbid sign, although many patients remain fully conscious until immediately before a fatal cardiac arrest.

The clinical severity markers that should alert the assessing doctor to the presence of a life-threatening attack are outlined 
Table 4 Levels of severity of acute asthma exacerbations

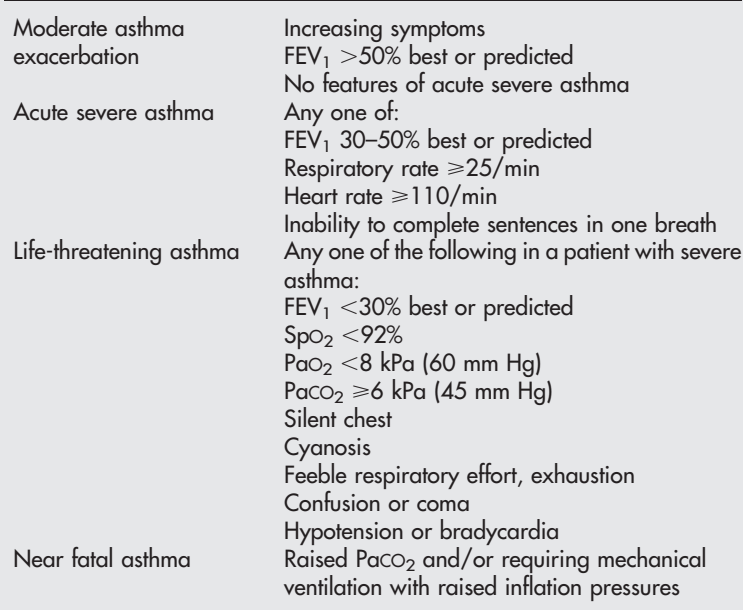

$\mathrm{FEV}_{1}$, forced expiratory volume in $1 \mathrm{~s} ; \mathrm{PaO}_{2}, \mathrm{PaCO}_{2}$, arterial oxygen and carbon dioxide tension; $\mathrm{SpO}_{2}$, oxygen saturation.

Modified from table 4 in the British Guideline on the Management of

Asthma.

in table 4. While these criteria appear practical and simple to apply, they have inherent limitations. ${ }^{26}$ First, the clinical symptoms and signs of severe asthma often do not correlate with the severity of physiological impairment and, as a result, their absence is not necessarily reassuring. Another limitation is that the components do not develop simultaneously or at unique levels of impairment. It is recommended that it is wise to base management on the "worst" abnormality and not be reassured because another feature does not fall within the definition of severe. ${ }^{18}$ In this way, some patients may be admitted unnecessarily or be overtreated, but some "preventable" deaths from asthma can be avoided.

\section{ASSESSMENT}

\section{Lung function tests}

Lung function tests are the basis for assessment of the severity of the asthmatic attack (table 4). ${ }^{31822}$ Preferably, this should be undertaken by spirometry with measurement of the forced expiratory volume in $1 \mathrm{~s}\left(\mathrm{FEV}_{1}\right)$ expressed as a percentage of predicted normal values. The National Health and Nutrition Examination Survey (NHANES) reference prediction equations should be used rather than the traditional European Coal and Steel normal values which are now acknowledged to be out of date and underestimate normal reference values by about $15 \%{ }^{30}$

Measurement of the peak expiratory flow (PEF), with values expressed as predicted normal values, represents an alternative if spirometry is not available. The normal reference values sourced from the Nunn and Gregg nomogram are recommended for the calculation of "percent predicted" PEF values. ${ }^{31}$ Contrary to current dogma, the PEF and FEV 1 are not equivalent when expressed as a percentage of predicted values, with the $\mathrm{FEV}_{1}$ being on average 5-10 percentage points lower than the PEF (ie, $\mathrm{FEV}_{1}$ of $30 \%$ predicted is equivalent to PEF of $35-40 \%) .^{32}{ }^{33}$ There is also marked intra-patient variability in the relationship, with $95 \%$ confidence intervals of around 50 percentage points. This means that major differences in the classification of asthma severity may occur (and the treatment recommended on the basis of this classification), depending on the lung function measurement used. This caution particularly applies to the assessment and management of life-threatening asthma in which $\mathrm{FEV}_{1}$ values are $4-10 \%$ lower than the PEF across the $\mathrm{FEV}_{1}$ range of $20-33 \%$ predicted. ${ }^{34} 35$
While recognising the poor correlation between clinical signs and physiological measures, an $\mathrm{FEV}_{1}$ of $<30 \%$ predicted is likely to be present in a patient who is unable to speak more than a few words with an arterial carbon dioxide tension $\left(\mathrm{PaCO}_{2}\right)$ of $>5.3 \mathrm{kPa}(40 \mathrm{~mm} \mathrm{Hg})$, a quiet chest with the absence of audible wheezing, respiratory rate $>30 / \mathrm{min}$ or pulsus paradoxus $>20 \mathrm{~mm} \mathrm{Hg.}{ }^{21} 3637$

Importantly, the magnitude of the improvement in lung function following initial bronchodilator treatment represents the most informative measure of severity of the acute episode and likely requirement for hospital admission. ${ }^{38}$ As a result, severity may be best defined in terms of outcome rather than the patient's initial presentation. ${ }^{26}$

If one accepts that the $\mathrm{FEV}_{1}$ is the "gold standard" method of assessing airflow obstruction in asthma, and that lung function measurements are essential in the assessment of asthma, a strong case can be made for the provision of spirometers in all hospital emergency departments. This case is further strengthened when one considers the use of spirometry in the assessment of other respiratory disorders and the costs and relative benefits of other medical equipment used in emergency departments. Peak flow measurements are preferred for monitoring lung function following admission to the ward.

While the measurement of the magnitude of hyperinflation is not indicated in the acute setting, it is informative to be aware that, in severe asthma, the residual volume can approach $400 \%$ and functional residual volume can be double the expected values. ${ }^{37}$

\section{Oxygen assessment and other tests}

Measurement of oxygen saturation by pulse oximetry should be undertaken in all patients with severe asthma presenting to hospital. In the absence of oxygen therapy, arterial desaturation and hypercarbia occur concurrently and normally only develop in life-threatening asthma. ${ }^{37}$ As a result, pulse oximetry is a suitable means for the routine assessment of ventilatory status. Analysis of arterial blood gases can be selectively reserved for those patients with oxygen saturations on room air of $<92 \%{ }^{39}$ or those who do not respond to initial treatment, with the FEV remaining $<30 \%{ }^{38}$

In the interpretation of arterial blood gases, attention focuses primarily on the $\mathrm{PaCO}_{2}$ with a normal value in a breathless asthmatic being a warning sign of impending hypoventilation and values above $6 \mathrm{kPa}(45 \mathrm{~mm} \mathrm{Hg}$ ) indicating a life-threatening attack and probable need for transfer to a high dependency unit (HDU) or intensive care unit (ICU, table 4). Fortunately, arterial oxygen tensions $<6.7 \mathrm{kPa}(50 \mathrm{~mm} \mathrm{Hg})$ or carbon dioxide tensions $>6 \mathrm{kPa}$ ( $45 \mathrm{~mm} \mathrm{Hg}$ ) occur infrequently, being present in less than $10 \%$ of patients attending the emergency department with severe asthma. ${ }^{26}{ }^{36}$

A chest radiograph is not routinely needed in an adult asthmatic attending the emergency department, being reserved for those who do not respond to initial treatment or in whom an alternative diagnosis such as pneumothorax or pneumonia is suspected. ${ }^{40}{ }^{41}$ The serum potassium concentration should be measured, particularly in patients with prior corticosteroid or diuretic treatment. Hypokalaemia caused primarily by highdose $\beta$-agonist therapy is not uncommon in severe asthma and may require potassium supplementation. Other investigations include a full blood count and electrocardiography in older patients. Microbiological investigations are seldom required, although purulent sputum should be cultured if present.

\section{MANAGEMENT}

The mainstay of treatment during the acute attack is supplementary oxygen, repeated inhaled bronchodilator and systemic corticosteroids (table 5). 




\section{Oxygen therapy}

Although it is recommended that high-flow oxygen is administered to all patients presenting with severe asthma, there is some evidence to suggest that this approach should be modified. First, best practice indicates that oxygen should be prescribed in the dose required to relieve hypoxaemia, guided by measurements of oxygen saturation obtained by oximetry and/or arterial blood gases and not prescribed at high flow to all patients with respiratory difficulties regardless of need. The administration of excessive oxygen is not without potential risks, including atelectasis and increased intrapulmonary shunting, and a reduction in cardiac output and coronary blood flow. ${ }^{42}$ Although carbon dioxide retention associated with high-flow oxygen therapy is not considered to occur in asthma, one small study raised the possibility that the administration of $100 \%$ oxygen to acutely ill asthmatics can induce or worsen carbon dioxide retention, particularly in patients with severe airway obstruction. ${ }^{43}$ Another concern which is not widely recognised is that the use of high-flow oxygen has the potential to lead to a delay in recognising deteriorating respiratory function. ${ }^{44}{ }^{45}$ This delay is caused by the patient maintaining $100 \%$ oxygen saturations despite progressive clinical deterioration so that, when the oxygen saturations begin to fall, the deterioration is recognised late and the opportunity to "buy time" by increasing the oxygen concentration is not available. As a result, supplementary oxygen should only be prescribed in severe asthma if the patient is hypoxic with the flow adjusted to achieve saturations greater than $92 \%$.

Heliox is a mixture of helium and oxygen which has been used in the treatment of severe asthma. The rationale is that its lower density results in increased airflow and reduced work of breathing. Some studies, ${ }^{46}{ }^{47}$ but not all, ${ }^{48}$ have reported benefits in patients with severe asthma. However, systematic reviews ${ }^{49} 50$ suggest that there is not yet sufficient evidence to recommend heliox as a routine treatment for severe asthma in the emergency department, perhaps to be reserved for those with refractory attacks.

\section{Non-invasive positive pressure ventilation (NIPPV)}

While non-invasive ventilation has a well established role in the management of exacerbations of chronic obstructive pulmonary disease, its role in the management of severe asthma is less clearly defined. Although early reports are encouraging, ${ }^{51}{ }^{52}$ NIPPV does not yet have a place in current management guidelines. It has been suggested, however, that it may be useful in those patients with hypercapnic respiratory failure as long as they are protecting their own airways and are able to tolerate the face mask. For those patients who are able to tolerate the positive pressures, NIPPV can reduce the work of breathing and respiratory muscle fatigue, thereby buying time for transfer to an ICU/HDU and for pharmacological intervention to take effect. There is also some evidence to suggest that it might decrease airways resistance, re-expand atelectatic areas of the lung and decrease the adverse haemodynamic effects of the large negative inspiratory pleural pressures. ${ }^{52}$ Although it may prevent invasive ventilation in some patients, there is concern that it may delay timely intubation in deteriorating patients. For those in whom it is indicated and tolerated, bilevel NIPPV should be started with $5 \mathrm{~cm} \mathrm{H}_{2} \mathrm{O}$ continuous positive airway pressure (CPAP) and $10 \mathrm{~cm} \mathrm{H}_{2} \mathrm{O}$ pressure support (equivalent to inspiratory positive airway pressure of $15 \mathrm{~cm} \mathrm{H}_{2} \mathrm{O}$ ) with the inspired oxygen titrated to achieve an oxygen saturation $>92 \%$. Adjustments should be made to optimise patient comfort.

\section{Inhaled bronchodilators}

Inhaled $\beta$-agonists are the mainstay of bronchodilator therapy, with the dose and frequency determined by the severity of the asthma attack and the response to treatment. With respect to bronchodilator treatment, the key points are:

(1) In addition to increasing the total dose of $\beta$-agonist administered, increasing the frequency of administration also leads to a greater bronchodilator efficacy. However, there is no advantage to the repeat administration of doses of nebulised salbutamol of $>2.5 \mathrm{mg}$ every $20 \mathrm{~min} .^{53}$ This regime has equivalent bronchodilator efficacy to $7.5 \mathrm{mg}$ salbutamol every $20 \mathrm{~min}$ in acute severe asthma. If there is an inadequate response to this regime, the best option is to proceed to continuous $\beta$-agonist nebulisation. ${ }^{23} 54$

(2) Metered dose inhalers with a holding chamber (spacer) produce outcomes that are at least equivalent to nebuliser therapy in severe asthma. ${ }^{55-57}$ This finding includes those with life-threatening asthma, with an $\mathrm{FEV}_{1}<30 \%$ predicted on presentation. As a guide, $400 \mu \mathrm{g}$ salbutamol via a spacer can be considered equivalent to a $2.5 \mathrm{mg}$ dose of salbutamol via nebuliser. It is suggested that the $\beta$-agonist should be actuated into a spacer in individual puffs, inhaled by tidal breathing or single breaths. The frequency of treatments is adjusted to the individual patient response, as occurs with nebuliser therapy. The previous British recommendation of 50 puffs of $\beta$-agonist via a metered dose inhaler and spacer in a life-threatening attack of asthma can be considered excessive. ${ }^{1}$

(3) The addition of ipratropium bromide to inhaled $\beta$-agonist therapy provides an increase in the bronchodilator response in severe asthma. ${ }^{58} 59$ This additional bronchodilation has now been shown with multiple dose regimes (as well as the administration of single doses), leading to both an improvement in lung function and a reduction in the requirement for hospital admission. In the absence of an established dose-response relationship in severe asthma, a $500 \mu \mathrm{g}$ dose can be administered by nebulisation if there is a poor initial response to inhaled $\beta$-agonist therapy, repeated after $60 \mathrm{~min}$ if there is minimal interval improvement. The standard dose of nebulised ipratropium bromide is $500 \mu \mathrm{g}$ 6hourly. The absolute benefit of ipratropium bromide in combination with a $\beta$-agonist is achieved in patients with the most severe airflow obstruction. One important indication for the use of anticholinergic bronchodilators is as first-line treatment for $\beta$-blocker induced attacks. ${ }^{60}$

(4) Bronchodilator nebuliser solutions should be administered from preservative-free sterile unit dose vials. ${ }^{61}$ The use of multidose nebuliser solutions with the preservative benzalkonium chloride should be avoided as such preparations 
have the potential to reduce the magnitude of bronchodilation or cause paradoxical bronchoconstriction. ${ }^{62}{ }^{63}$

(5) There is preliminary evidence to suggest that salbutamol nebuliser solution administered with isotonic magnesium sulphate results in a greater bronchodilator response than the standard isotonic salbutamol solution. ${ }^{64}{ }^{65}$ The greatest efficacy with the adjuvant magnesium solution occurs in those with life-threatening asthma, defined by a baseline $\mathrm{FEV}_{1}$ of $<30 \%$ predicted. Further research is now needed to determine whether salbutamol nebuliser solution with adjuvant magnesium should become the preferred agent for the treatment of severe asthma. Regrettably, there is no commercially available salbutamol solution which incorporates isotonic magnesium for use.

(6) In life-threatening asthma the greatest bronchodilator response to nebulised $\beta$-agonist is achieved with continuous administration. For example, $2.5 \mathrm{mg}$ at $30 \mathrm{~min}$ intervals for $2 \mathrm{~h}$ results in a lesser degree of bronchodilation than the same dose $(10 \mathrm{mg}$ in $70 \mathrm{ml}$ ) administered continuously over the $2 \mathrm{~h}$ period in those with lifethreatening asthma. ${ }^{66}$ There appears to be no benefit in nebulising higher concentrations continuously. ${ }^{54}$

(7) In view of the theoretical risk of oxygen desaturation while using air-driven compressors to nebulise $\beta$-agonists, oxygen-driven nebulisers are the preferred method of delivery. The absence of supplemental oxygen should not prevent nebulised therapy from being administered. ${ }^{67}$

One regimen which incorporates these features is the administration of $2.5 \mathrm{mg}$ salbutamol via nebulisation every $20 \mathrm{~min}$ for $\mathrm{l} \mathrm{h}$ (or $400 \mu \mathrm{g}$ salbutamol by metered dose inhaler with spacer) as the initial bronchodilator treatment for severe asthma, with the frequency of further administration and the use of ipratropium bromide and/or intravenous magnesium determined by the response to treatment. In patients with lifethreatening asthma, continuous nebulised salbutamol should be undertaken with the co-administration of nebulised ipratropium bromide every $60 \mathrm{~min}$.

\section{Intravenous bronchodilators}

It is with the intravenous administration of bronchodilators that the major changes in management have occurred over the last decade.

(1) Current evidence does not support the use of intravenous $\beta$ agonists in patients with severe asthma as its use does not result in greater benefit than repeat nebulised $\beta$-agonist. ${ }^{68-70}$ The role of intravenous $\beta$-agonist in addition to nebulised $\beta$-agonist has not been adequately studied, nor has its role in ventilated patients. As a result, its use should be restricted to patients with refractory life-threatening asthma as an adjunct to conventional intensive treatment. The recommended dose of salbutamol when administered by intravenous dose infusion is $200 \mu \mathrm{g}$ over $10 \mathrm{~min}$, followed by an infusion of $0.1-0.2 \mu \mathrm{g} / \mathrm{kg} / \mathrm{min}$ with the rate of the infusion adjusted according to the therapeutic response.

(2) Adding intravenous theophylline to repeated administration of $\beta$-agonist via a nebuliser does not increase the efficacy but does increase the risk of side effects. ${ }^{71}$ No subgroups in which aminophylline might be more effective have been identified. As with the use of intravenous $\beta$ agonists, its use should be restricted to patients with refractory life-threatening asthma as an adjunct to conventional intensive treatment. Intravenous aminophylline is given in a dose of $6 \mathrm{mg} / \mathrm{kg}$ over $30 \mathrm{~min}$, then infused in the dose range $0.5-0.9 \mathrm{mg} / \mathrm{kg} / \mathrm{h}$. A loading dose should not be given to patients who are already receiving oral theophylline. The maintenance infusion rate is altered according to plasma theophylline levels, which should be measured within $24 \mathrm{~h}$. For the continuous infusion, lower doses may be required in patients with liver disease or cardiac failure and those taking cimetidine, ciprofloxacin or erythromycin. Higher doses may be required in smokers.

(3) The use of intravenous magnesium can now be recommended in patients with life-threatening attacks. ${ }^{72}$ Its use leads to an improvement in lung function and a reduction in hospital admissions in those who respond poorly to initial treatment, but not those with less severe asthma responding to initial treatment. Currently, the evidence relates to a single dose $\left(2 \mathrm{~g} \mathrm{MgSO}_{4}\right.$ diluted in $50 \mathrm{ml} 0.9 \%$ normal saline administered over $30 \mathrm{~min}$ ) and the efficacy of a continuous infusion or repeated dose has yet to be determined. As a result of these studies, if an intravenous bronchodilator is to be administered, current evidence favours the use of intravenous magnesium rather than intravenous $\beta$-agonist or aminophylline.

\section{Systemic corticosteroids}

Systemic corticosteroids administered on presentation to the emergency department markedly reduce the need for hospital admission in patients with severe asthma. ${ }^{73}$ The benefits are greatest in patients with life-threatening asthma and those not currently receiving steroids. Significant benefit with systemic steroid therapy is observed within $4 \mathrm{~h}$ of administration.

The major issue that has been clarified over recent years is the optimal dose and route of administration. It has been shown that there is no benefit in using very high intravenous doses in severe asthmatics needing hospital admission. ${ }^{74}$ In this meta-analysis, no additional benefit was observed with doses of $>50 \mathrm{mg}$ prednisolone or $200 \mathrm{mg}$ hydrocortisone per day. In terms of lower doses, the most informative double-blind randomised study has shown that intravenous hydrocortisone $50 \mathrm{mg}$ four times a day for two days, followed by prednisone $20 \mathrm{mg}$ daily, is as effective in resolving acute severe asthma as either hydrocortisone $200 \mathrm{mg}$ or $500 \mathrm{mg}$ four times daily followed by prednisone 40 or $60 \mathrm{mg}$ daily, respectively. ${ }^{75}$ These findings apply to the situation of life-threatening asthma, as the presentation $\mathrm{FEV}_{1}$ was $19 \%$ predicted and similar efficacy between the three treatment groups was observed in the subgroup whose $\mathrm{FEV}_{1}$ after initial bronchodilator treatment remained $<30 \%$ predicted.

Several studies have shown a similar efficacy with oral and intravenous steroids in severe asthma, suggesting that intravenous treatment is often unnecessary. ${ }^{76}{ }^{77}$ This is because of the rapid absorption of prednisolone and its high bioavailability. When the added costs and potential minor complications of intravenous treatment are considered, these results support the initial use of oral steroids, except in patients who are vomiting or too breathless to swallow or in those in whom an intravenous line is already in place or is required. Thus, initial treatment with intravenous hydrocortisone $100 \mathrm{mg}$ stat and/or 30-60 mg prednisone is likely to be adequate with subsequent treatment determined by the response.

\section{Inhaled corticosteroids}

One issue that has not been resolved is the role of high-dose inhaled corticosteroids as an adjunct to-or in place ofsystemic corticosteroids in asthma. ${ }^{78}$ It has been shown that a 2 week course of high-dose inhaled corticosteroid (eg, fluticasone $2000 \mu \mathrm{g} /$ day) may be as effective as a course of oral steroids (prednisolone starting at $40 \mathrm{mg}$ and reducing by $5 \mathrm{mg}$ every other day) in the treatment of mild to moderate 
exacerbations not requiring hospital admission (presentation PEF $>60 \%)^{79}$

However, it has recently been reported that, in adults with severe asthma, the use of repeated high doses of inhaled corticosteroids (fluticasone propionate $3000 \mu \mathrm{g} / \mathrm{h}$ administered by metered dose inhaler and spacer for $3 \mathrm{~h}$ ) was more effective than intravenous hydrocortisone $(500 \mathrm{mg}) .^{80}$ This therapeutic benefit was evident within 90 min of presentation at the emergency department and was particularly marked in those patients with more severe airways obstruction in which there was a significant reduction in hospitalisation rate. It was proposed that the beneficial effect may be related to vasoconstriction and possibly mucosal decongestion rather than modulation of gene expression because of the time course of the benefit.

It has yet to be determined whether inhaled corticosteroid treatment provides additional benefit when used in combination with standard systemic steroids for severe asthma. However, it may be worthwhile following a pragmatic approach of administering high-dose inhaled corticosteroids in addition to systemic steroids in patients with life-threatening asthma who respond poorly to conventional treatment.

\section{RESPONSE TO TREATMENT}

The response to treatment determines both the further treatment requirements and the need for hospital admission. ${ }^{38}{ }^{81}$ Assessment of the response is based on repeat clinical examination, lung function tests and oximetry. Of these, the magnitude of improvements in $\mathrm{FEV}_{1}$ and absolute $\mathrm{FEV}_{1}$ values following bronchodilator treatment are the best indicators of requirement for admission and likely relapse at discharge. The initial $\mathrm{FEV}_{1}$, clinical signs or laboratory parameters such as arterial blood gas measurements are less reliable as predictive indices than post-bronchodilator $\mathrm{FEV}_{1}$. In part this is because small improvements in the degree of airflow obstruction in severe asthma may produce substantial changes in clinical signs and symptoms, with dyspnoea normally resolving once the $\mathrm{FEV}_{1}$ reaches only $50 \%$ of the predicted normal value. ${ }^{37}$ As a result, severity may be best measured as the response in lung function to high-dose inhaled bronchodilator therapy rather than in terms of the patient's initial presentation.

\section{ICU TRANSFER}

Patients with features of potentially life-threatening asthma who are not responding to treatment, or those with features suggesting that they are at imminent risk of death, should be admitted to an ICU or HDU if adequate facilities are available (table 4). Transfer to such units will ensure that these patients are intensively monitored and can be ventilated without delay should the need arise. Early referral, before the need for ventilation arises, usually makes the process easier. The intensive care management of life-threatening asthma including invasive ventilation is beyond the scope of this review, but it has been reviewed elsewhere. ${ }^{82} 83$

\section{WARD ADMISSION}

If repeated bronchodilator treatment does not increase the $\mathrm{FEV}_{1}$ to $>50-60 \%$ predicted, or if clinical features of severe asthma persist, admission is recommended. Patients may also require admission if, despite achieving an $\mathrm{FEV}_{1}>60 \%$, there are other concerns, as outlined in table $6 .^{3}$ Depending on resources, admission to a respiratory ward is preferable as this is likely to lead to a higher standard of care and better outcome than admission to a general medical ward ${ }^{84}$

A doctor and/or nurse should remain with the patient after initial treatment has started, or at least until clear improvement is seen. The patient should be assessed regularly, with

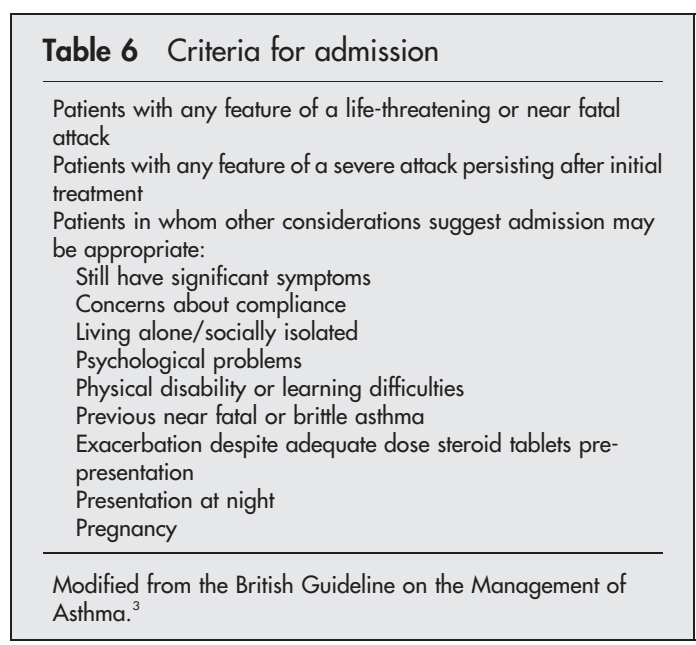

measurement of lung function and heart rate. The frequency of these measurements will be dictated by the response-at least every 15 min initially. Once improvement has occurred, a suitable regimen would be to monitor these measurements before and after bronchodilator treatment. Patients who are stable can be transferred to a medical ward where oxygen can be continued if hypoxic and nebulised $\beta$-agonists given every 2 $4 \mathrm{~h}$. There is no major advantage in continuing inhaled ipratropium bromide treatment beyond the initial $12-24 \mathrm{~h}$ period..$^{85}$

Oral steroids should be continued throughout the admission. A single morning dose of steroid may not adequately protect the circadian narrowing of the airways experienced at night. The peak effect of oral steroids occurs at around $9 \mathrm{~h}$ and then declines and, as a result, may not provide sufficient effect throughout the $24 \mathrm{~h}$ dosing interval. ${ }^{86}$ The clinical significance of this time course of effect is suggested by a small study in which a small dose of prednisolone given at 15:00 hours was shown to be more effective in protecting against nocturnal bronchoconstriction than an 08:00 or 20:00 hours dosing regime. ${ }^{87}$ To overcome this problem, the preferred dosing regime in hospital is twice daily, in contrast to the once morning regime routinely used as an outpatient. As discussed, the effective daily dose of oral prednisolone is between 30 and $50 \mathrm{mg} .{ }^{88}$

On average, it takes 7-10 days for symptoms and lung function to stabilise after an asthma exacerbation and, for this reason, a 10-14 day course is usually recommended. Unless the patient is on maintenance oral steroids, tapering the dose at the end of the course is unnecessary. Studies comparing abrupt cessation with a tapering regime found no difference in lung function or relapse rate between the two groups. ${ }^{89} 90$ Suppression of the hypothalamic pituitary axis is not clinically significant after a short course in a patient who is not on maintenance steroids.

Treatment with inhaled corticosteroids should be continued throughout the admission as there is evidence that it may have efficacy in this situation ${ }^{79} 80$ and to reinforce the importance of this long-term treatment to patients.

The prescription of sedatives has been associated with sudden death due to their effect in reducing respiratory drive and alertness, and they are therefore contraindicated outside the ICU. ${ }^{13}{ }^{14}$ Percussive physiotherapy is likely to distress a severely ill asthmatic patient and is contraindicated in the initial stages, although relaxation techniques to achieve control over the rate, depth and pattern of breathing may be helpful in the recovery phase. 


\section{Asthma assessment sheet}

To be placed in the accident and emergency department notes and a copy in the patient's hospital records. If discharged, copies to be given to patient and sent to GP

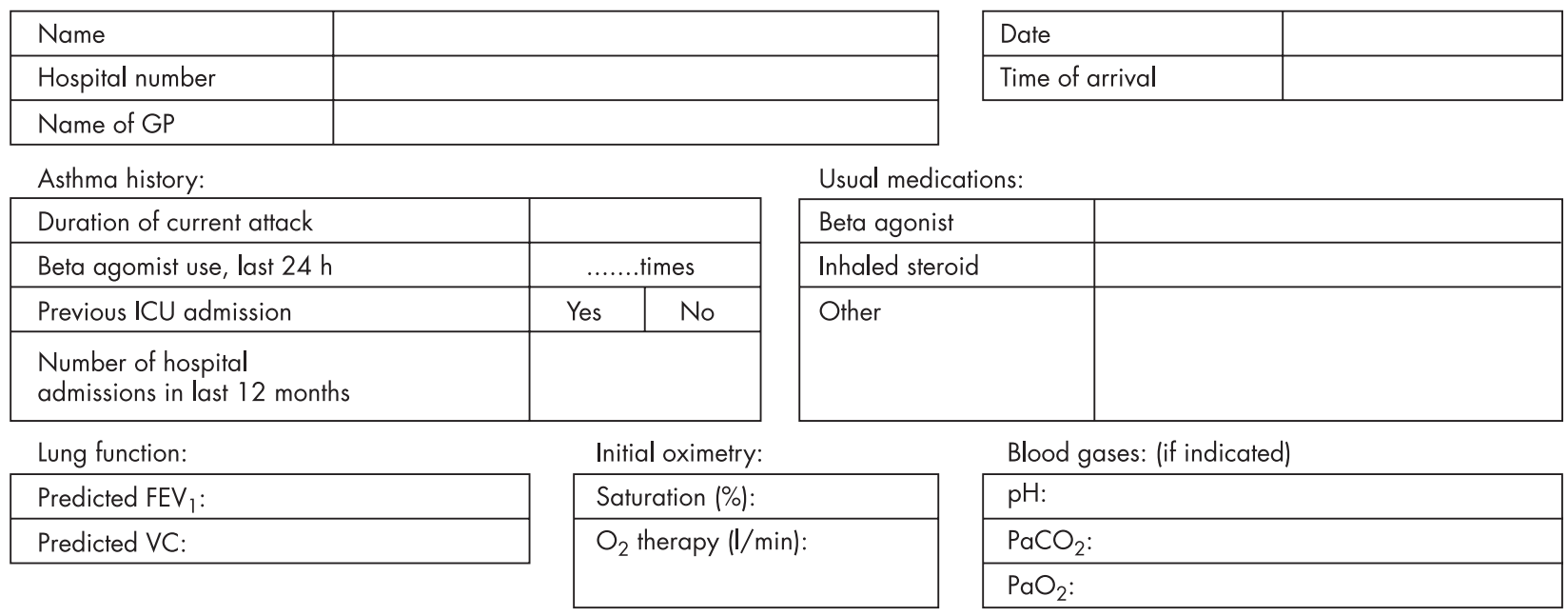

Progress report:

\begin{tabular}{|l|r|r|r|r|}
\hline Data & Initial assessment & Post-nebuliser (1) & Post-nebuliser (2) & Final assessment \\
\hline Time & & & & \\
\hline Difficulty talking & & & & \\
\hline Respiratory rate & $\mathrm{L}$ & $\mathrm{L}$ & $\mathrm{L}$ & \\
\hline Pulse rate & $\%$ & $\%$ & $\%$ & $\mathrm{~L}$ \\
\hline $\begin{array}{l}\mathrm{FEV} \text { litres } \\
\text { \% Pred }\end{array}$ & $\mathrm{L} / \mathrm{min}$ & $\mathrm{L} / \mathrm{min}$ & $\mathrm{L} / \mathrm{min}$ & \\
\cline { 2 - 5 } $\mathrm{O}_{2}$ Sats & & & & $\mathrm{L} / \mathrm{min}$ \\
$\mathrm{O}_{2}$ Therapy & & & & \\
\hline Treatment given & & & & \\
& & & & \\
\end{tabular}

Outcome:

Discharge medications:

\begin{tabular}{|l|l|l|l|}
\hline Admitted & Ward & Bronchodilator & \\
\hline Discharged & & Inhaled steroid & \\
\hline Date to see GP & & Oral prednisone & \\
\hline Predicted PEF & & Inhaler technique & \\
\hline Pre-discharge PEF & & \\
\cline { 1 - 1 } $\begin{array}{l}\text { Urgent medical help } \\
\text { to be sought if PEF }\end{array}$ & & \begin{tabular}{l} 
Name of doctor: \\
\hline Self-managment plan
\end{tabular} & Signature: \\
\hline
\end{tabular}

Figure 1 Asthma Assessment Sheet currently in use in the Wellington Hospital Emergency Department, Wellington, New Zealand. FEV 1 , forced expiratory volume in $1 \mathrm{~s}$; ICU, intensive care unit; $\mathrm{VC}$, vital capacity; $\mathrm{PaCO}_{2}$, arterial carbon dioxide tension; $\mathrm{PaO}_{2}$, arterial oxygen tension; $\mathrm{PEF}$, peak expiratory flow.

Antibiotics should not be routinely prescribed as bacterial infections seldom provoke exacerbations (in contrast to viral respiratory tract infections), and their routine prescription does not influence outcome in exacerbations of asthma. ${ }^{91}$ Consideration may need to be given to use of a macrolide if chronic Mycoplasma or Chlamydia pneumoniae infection are suspected in chronic unstable disease; however, data to support this approach are not yet conclusive. ${ }^{92}$

It is difficult to determine the optimal duration of hospital stay for an admission for severe asthma. Because of the widespread under-resourcing of medical inpatient beds, there is often considerable management pressure to discharge patients early. However, in the case of asthma, this approach is not without risk, not least because there is an increased risk of early relapse and readmission in the two to three months after admission. ${ }^{93}$ Perhaps the best predictor of outcome is the PEF variability in the $24 \mathrm{~h}$ before discharge, for which it has been shown that a diurnal variation in PEF of $>20 \%$ is associated with an increased risk of further severe attacks requiring repeat hospital admission..$^{94}$ 
(A): $\quad$ The asthma management protocol currently in use in the Wellington Hospital Emergency Department

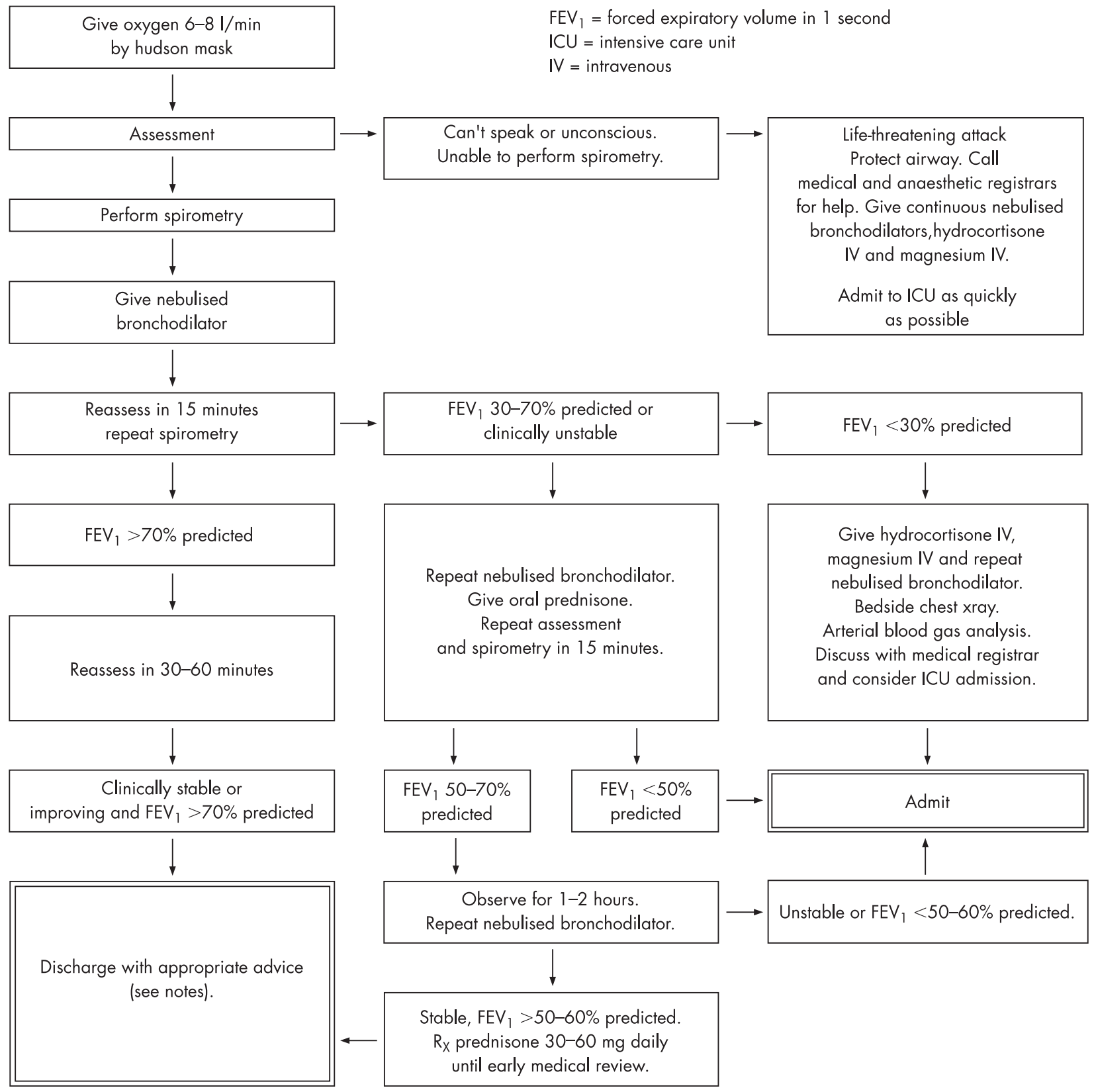

Figure 2 (A) Asthma management protocol and (B) Information Sheet currently in use in the Wellington Hospital Emergency Department, Wellington, New Zealand.

One approach which facilitates early discharge is the use of nebulised $\beta$-agonist treatment according to an "as required" regime rather than a regular 4-hourly regime from $24 \mathrm{~h}$ after hospital admission. ${ }^{95}$ Implementation of this "as required" regime has similar efficacy but results in an average reduction in the length of hospital stay of about 1 day. This outcome is achieved with about half the total dose of $\beta$-agonist administered, a reduced incidence of side effects and a strong patient preference for this regime. At least $24 \mathrm{~h}$ before scheduled discharge, the patient should be changed from nebulised to their routine aerosol or dry powdered metered dose inhaler to ensure that clinical stability is maintained on this lower dose of $\beta$-agonist.

As improvement is achieved, the emphasis shifts to investigation of the causes and circumstances of the severe attack, and arrangements are made for management following discharge, long term treatment, the institution of a self-management plan and appropriate follow-up arrangements.

\section{DISCHARGE ARRANGEMENTS}

Whether the discharge occurs from the emergency department or hospital ward, it is crucial that doctors address the problems 
(B): $\quad$ Guidelines for the initial management of asthma in adults

(notes to accompany management protocol)

Treatment

1. Nebulised bronchodilators

Salbutamol (ventolin) $2.5 \mathrm{mg}$ nebulised, using oxygen at 6-8 I/min, until finished.

If there is a poor response to initial nebulised treatment, salbutamol can be administered either continuously, or $2.5 \mathrm{mg}$ every 20 min with the addition of ipratropium bromide up to $0.5 \mathrm{mg}$ hourly.

2. Corticosteroid therapy

a. Hydrocortisone $100 \mathrm{mg}$ intravenous stat, and/or

b. Prednisone $30-60 \mathrm{mg}$ orally stat.

3. Parenteral magnesium therapy

Magnesium sulphate (IV influsion 1.2-2 $\mathrm{g} \mathrm{MgSO}_{4}$ in $100 \mathrm{mls} \mathrm{N} /$ saline over 20 mins)

Pre-discharge considerations

1. Before discharge, consider whether the patient needs

- a coure of oral prednisone, 30-60 mg daily, until early medical review

- to start or increase the dose of inhaled corticosteroid

- specialist referral, if high-risk asthmatic

2. Before discharge, ensure that the patient

- can use their inhalers correctly patiently and has a supply of their medications

- has been advised to make an early follow-up appointment with their GP

- has a peak flow meter and knows at what level to contact emergency medical help

- has a copy of the assessment sheet

- has an asthma self-management plan in place

Note:

These are guidelines only and may not suit all patients. If there is any doubt about a particular patient, discuss with the ED consulant or medical registrar. Admit any patient who is unstable regardless of the $\mathrm{FEV}_{1}$.

that may have led to the hospital admission. Patients admitted to hospital with asthma and those who make frequent attendances at the emergency department are recognised as a particularly high-risk group of patients who have poor selfmanagement skills and often have inadequate medical followup in the community. For this reason, doctors should ensure that patients are prescribed regular inhaled corticosteroids and that their inhaler technique is checked before discharge. It is also worthwhile to provide simple advice on what to do if their asthma worsens again. This can be achieved by giving patients a peak flow meter with instructions concerning the level at which to seek medical care either from their GP or, if necessary, the emergency department. Doctors are also encouraged to prescribe a course of oral steroids, based on the evidence that in this situation it greatly improves outcome with a fourfold reduction in relapse rate in the following week. ${ }^{96}$ This recent systematic review reported that about 15 patients need to be treated to prevent relapse requiring medical care after discharge from the emergency department with an exacerbation of asthma. ${ }^{96}$

Written communication with the GP via letter or email concerning the details of the ED attendance and/or hospital admission is essential to help address the problem of discontinuity of care. Alternatively, it may be advisable to phone if there is a delay in letters being typed and sent out, due to the high rate of relapse in the first week following discharge. Arrangements need to be made for medical follow-up both with the GP and with the respiratory specialist in the case of lifethreatening asthma. An open access self-admission service should be considered in patients who have experienced a lifethreatening or precipitate attack. The advantages of such a service, which may require prior arrangement with the ambulance service, have been shown. ${ }^{97}$

ASSESSMENT SHEETS AND TREATMENT PROTOCOLS

One approach which has been used to facilitate clinical practice in accordance with guidelines is the implementation of assessment sheets and treatment protocols. ${ }^{98-103}$ When used in the emergency department, they have been shown to identify rapidly individuals at risk of an adverse outcome, ensure a high standard of management, facilitate the appropriate referral to respiratory wards and medical ICU and improve outcomes such as length of stay and number of subsequent return visits. Treatment protocols are traditionally limited to algorithmbased flow charts, but the addition of an assessment sheet facilitates their implementation. This is particularly the case with severe asthma in which management is determined by asthma severity and in which doctors seem to have major difficulties in following this approach.

A guideline-based asthma assessment and associated treatment algorithm is shown in figs 1 and 2 . The assessment sheet is designed to encourage a quick focused history to identify baseline and acute risk, an objective assessment of asthma severity, and repeat clinical examination and measures of $\mathrm{FEV}_{1}$. The response to treatment can thus be assessed and a decision made on whether the patient requires admission or can be discharged. In this case, a structured approach is provided to address issues relating to long-term care and advice on when 


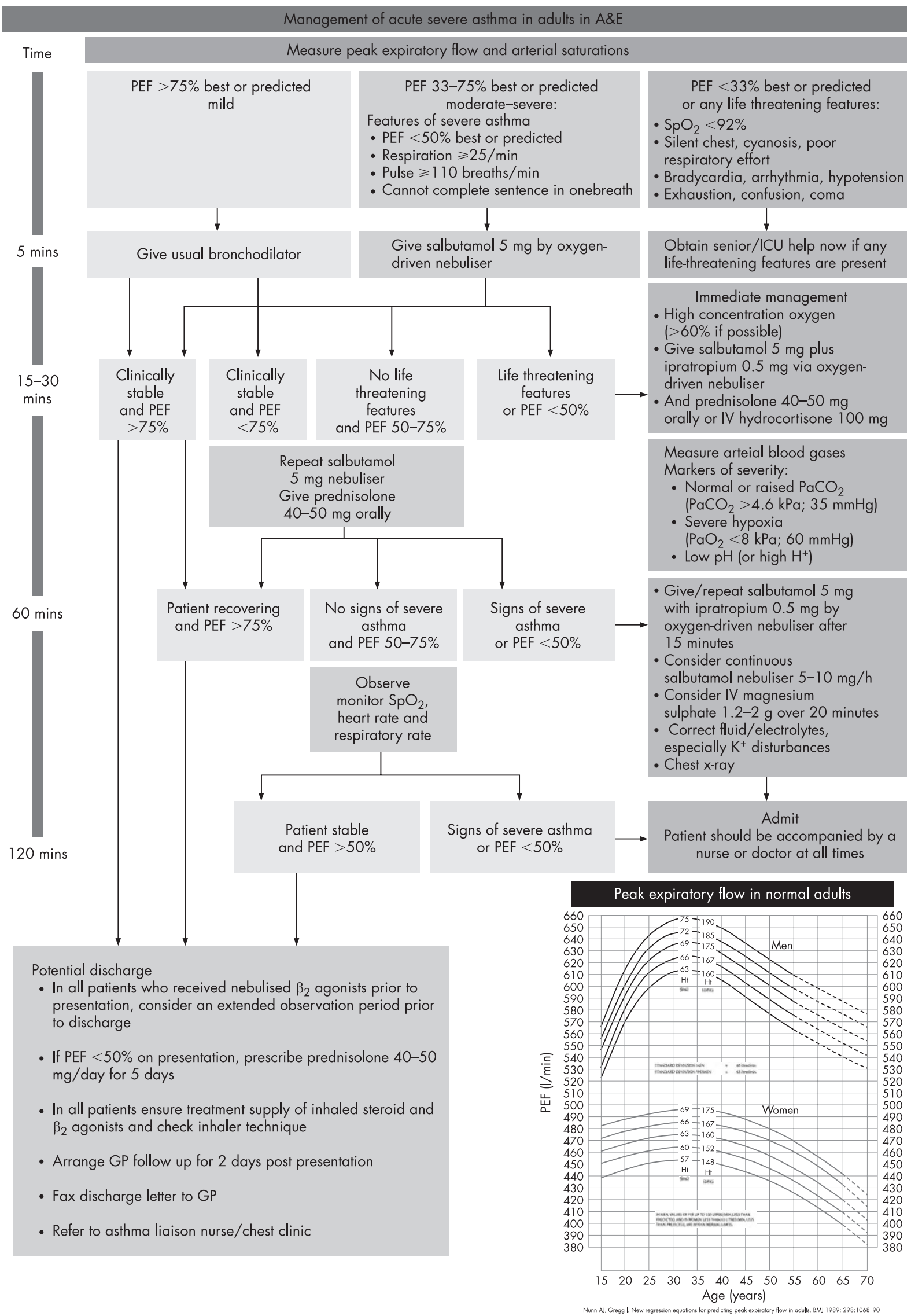

Figure 3 Management of acute severe asthma in adults in A\&E (reproduced from the British Guideline on the Management of Asthma). ${ }^{3}$ 


\section{Key points}

- The management of asthma in the emergency department can be improved through the use of simple assessment and treatment protocols.

- Assessment of asthma severity should be based primarily on the measurement of $\mathrm{FEV}_{1}$, expressed as the percentage of normal predicted values.

- For most patients, initial treatment with high-flow oxygen, nebulised $\beta$-agonist and oral corticosteroids is sufficient.

- Currently available evidence does not support the routine use of intravenous theophylline or intravenous $\beta$-agonist treatment in acute asthma; magnesium is the preferred intravenous bronchodilator in life-threatening asthma.

- Patients with any feature of a severe attack persisting after initial treatment should be admitted; patient circumstances should also be considered.

- For patients who are discharged, long-term management should be reviewed and medical follow-up arranged.

the patient should present again if their asthma deteriorates further.

The algorithm recommended in the British guidelines, based on peak flow, is shown in fig 3. Modification of the current protocols and assessment sheets for use in general practice is encouraged, where similar problems in the assessment and management of severe asthma may also be encountered. ${ }^{104}$

\section{CONCLUSIONS}

It is difficult to understand why there is such a huge discrepancy between the management of severe asthma recommended by evidence-based guidelines and that observed in clinical practice. The recommendations are relatively straightforward and have been widely promoted both in guidelines $^{1-3}$ and reviews. ${ }^{18} 2226{ }^{105}$ It is likely that the problems are related in part to the inexperience of the junior medical staff who are commonly delegated responsibility for the hospital care of patients with severe asthma, and to inadequate senior medical supervision. Specialist physicians need to be more proactive in their implementation of such guidelines through the use of locally derived protocols and assessment sheets, reinforced by audit.

\section{Authors' affiliations}

S Aldington, R Beasley, Medical Research Institute of New Zealand, Wellington, New Zealand

R Beasley, Wellington Hospital, Capital and Coast District Health Board, Wellington, New Zealand

Funding: None

Competing interests: None.

\section{REFERENCES}

1 British Thoracic Society. Guidelines for management of asthma in adults: II Acute severe asthma. BMJ 1990;301:797-800.

2 British Thoracic Society. Guidelines on the management of asthma. Thorax 1993;48(Suppl 1):S1-24.

3 British Thoracic Society/Scottish Intercollegiate Guidelines Network. British guideline on the management of asthma: a national clinical guideline. Thorax, 2003;58(Suppl I).

4 Pearson MG, Ryland I, Harrison BDW. Comparison of the process of care of acute severe asthma in adults admitted to hospital before and $1 \mathrm{yr}$ after the publication of national guidelines. Respir Med 1996;90:539-45.

5 Ulahannan T, Hardern RD, Hamer DW. Do accident and emergency senior house officers know the British guidelines on the management of acute asthma? Postgrad Med J 1996;72:162-3.
6 Hart SR, Davidson AC. Acute adult asthma: assessment of severity and management and comparison with British Thoracic Society Guidelines. Respir Med 1999;93:8-10.

7 Crane J, Pearce N, Burgess C, et al. Markers of risk of asthma death or readmission in the 12 months following a hospital admission for asthma. Int J Epidemiol 1992;21:737-44.

8 Rea HH, Scragg R, Jackson R, et al. A case-control study of deaths from asthma. Thorax 1986;41:833-9.

9 Turner MO, Noertiojo K, Vedal S, et al. Risk factors for near-fatal asthma: a case-control study in hospitalized patients with asthma. Am J Respir Crit Care Med 1998;157:1804-9.

10 Spitzer WO, Suissa $S$, Ernst $P$, et al. The use of $\beta$-agonists and the risk of death and near death from asthma. N Engl J Med 1992;326:501-6.

11 Marquette $\mathrm{CH}$, Saulnier $\mathrm{F}$, Leroy $\mathrm{O}$, et al. Long-term prognosis of near-fatal asthma: a 6-year follow-up study of 145 asthmatic patients who underwent mechanical ventilation for a near-fatal attack of asthma. Am Rev Respir Dis 1992; 148:76-81

12 Windom HH, Burgess CD, Crane J, et al. The self-administration of inhaled beta agonist drugs during severe asthma. NZ Med J 1990;103:205-7.

13 Hetzel MR, Clark TJH, Branthwaite MA. Asthma: analysis of sudden deaths and ventilatory arrests in hospital. BMJ 1977;1:808-11.

14 Bateman JAM, Clark SW. Sudden death in asthma. Thorax 1979;34:40-4.

15 Rodrigo GJ, Rodrigo C. Rapid-onset asthma attack: a prospective cohort study about characteristics and response to emergency department treatment. Chest 2000; 1 18:1547-52

16 Barr RG, Woodruff PG, Clark S, et al. Sudden-onset asthma exacerbations: clinical features, response to therapy, and 2-week follow-up. Eur Respir J 2000;15:266-73.

17 Salmeron S, Liard R, Elkharrat D, et al. Asthma severity and adequacy of management in accident and emergency departments in France: a prospective study. Lancet 2001;25:629-35.

18 Harrison BDW. Acute severe asthma. In: Gibson GJ, Geddes DM, Costabel U, et al, eds. Respiratory medicine. 3rd ed. Volume 2. Oxford: Elsevier Science, 2003:1378-95

19 Goldman J, Muers U. Vocal cord dysfunction and wheezing. Thorax 1991;46:401-4.

20 Christopher KL, Wood RP, Eckert RC, et al. Vocal cord dysfunction presenting as asthma. N Engl J Med 1983;308:1566-70.

21 Neville E, Gribbin H, Harrison BDW. Acute severe asthma. Respir Med $1991 ; 85: 463-74$.

22 Harrison BDW. Guidelines for management of acute asthma in adults. In: O'Byrn P, Thompson NC, eds. Manual of asthma management. London: WB Saunders \& Co, 1995:557-76.

23 Lin RY, Sauter D, Newman T, et al. Continuous versus intermittent albuterol nebulization in the treatment of acute asthma. Ann Emerg Med 1993;22:1847-53.

24 Rubinfeld AR, Pain MC. Perceptions of asthma. Lancet 1976;i:882-4.

25 Kendrick AH, Higgs CM, Whitfield MJ, et al. Accuracy of perception of the severity of asthma: patients treated in general practice. BMJ 1993;307:422-4

26 McFadden ER Jr. Acute severe asthma. Am J Respir Crit Care Med 2003:168:740-59.

27 Morris MJ. Asthma - expiratory dyspnoea? BMJ 1981;283:838-9

28 Martin JG, Shore SA, Engel LA. Mechanical load and inspiratory muscle action during induced asthma. Am Rev Respir Dis 1983;128:455-60.

29 Rebuck AS, Read J. Assessment and management of severe asthma. Am J Med 1971:51:788-98.

30 Roca J, Burgos F, Sunyer J, et al. Reference values for fixed spirometry. Eur Respir J 1998;11:1354-62

31 Nunn AJ, Gregg I. New regression equations for predicting peak expiratory flow in adults. BMJ 1989:298:1068-70.

32 Sawyer G, Miles J, Lewis S, et al. Classification of asthma severity: should the international guidelines be changed? Clin Exp Allergy 1998;28:1565-70.

33 Llewellin P, Sawyer G, Lewis S, et al. The relationship between FEV 1 and PEF in the assessment of the severity of airways obstruction. Respirology 2002;7:333-7.

34 Nowak RM, Tomlonorich MC, Sarker DD, et al. Arterial blood gases and pulmonary function testing in acute bronchial asthma: predicting patient outcomes. JAMA 1983;249:2043-6.

35 Harrison BDW, Swarbrick EJ. Peak flow percentage in asthma. Lancet $1971 ;$ ii: 492.

36 McFadden ER, Lyons HA. Arterial blood gas tensions in asthma. N Engl J Med 1968;278:1027-32.

37 McFadden ER, Kiser R, De Groot WJ. Acute bronchial asthma: relations between clinical and physiologic manifestations. N Engl J Med 1973;288:221-5.

38 Kelsen SE, Kelsen DP, Fleegler BF, et al. Emergency room assessment and treatment of patients with acute asthma. Adequacy of the conventional approach. Am J Med 1978;64:622-8.

39 Carruthers DM, Harrison BDW. Arterial blood gas analysis or oxygen saturation in the assessment of acute asthma. Thorax 1995;50:186-8.

40 Zieverink SE, Harper AP, Holden RW, et al. Emergency room radiography of asthma: an efficacy study. Radiology 1982;145:27-9.

41 White CS, Cole RP, Lubetsky HW, et al. Acute asthma: admission chest radiography in hospitalised adult patients. Chest 1991;100:14-6.

42 Thomson AJ, Webb DJ, Maxwell SRJ. Oxygen therapy in acute medical care: the potential dangers of hyperoxia need to be recognised. BMJ 2002;324:1406-7.

43 Chien JW, Ciufo R, Novak R, et al. Uncontrolled oxygen administration and respiratory failure in acute asthma. Chest 2000;117:728-33. 
44 Downs JB. Has oxygen administration delayed appropriate respiratory care? Fallacies regarding oxygen therapy. Respir Care 2003;48:611-20.

45 Downs JB, Smith RA. Increased inspired oxygen concentration may delay diagnosis and treatment of significant deterioration in pulmonary function. Crit Care Med 1999:27:2844-6.

46 Kass JE, Terregino CA. The effect of heliox in acute severe asthma: a randomized controlled trial. Chest 1999;116:296-300.

47 Manthous CA, Hall JB, Mclmed A, et al. Heliox improves pulsus paradoxus and peak expiratory flow in non-intubated patients with severe asthma. Am J Respir Crit Care Med 1995;151:310-4.

48 Henderson SO, Acharya P, Kilaghbian T, et al. Use of heliox-driven nebulizer therapy in the treatment of acute asthma. Ann Emerg Med 1999;33:141-6.

49 Ho AM, Lee A, Karmakar MJ, et al. Heliox vs air-oxygen mixtures for the treatment of patients with acute asthma: a systematic overview. Chest 2003; 123:882-90.

50 Rodrigo GJ, Rodrigo C, Pollack CV, et al. Use of helium-oxygen mixtures in the treatment of acute asthma: a systematic review. Chest 2003;123:891-6.

51 Soroksky A, Stav D, Shpirer I. A pilot prospective, randomized, placebocontrolled trial of bilevel positive airway pressure in acute asthmatic attack. Chest 2003;123:1018-25.

52 Meduri GU, Cook TR, Turner RE, et al. Non-invasive positive pressure ventilation in status asthmaticus. Chest 1996;1 10:767-74.

53 Emerman CL, Cydulka RK, McFadden ER. Comparison of 2.5 vs $7.5 \mathrm{mg}$ of inhaled albuterol in the treatment of acute asthma. Chest 1999:115:92-6.

54 Shrestha M, Bidadi K, Gourlay S, et al. Continuous vs intermittent albuterol, at high and low doses, in the treatment of severe acute asthma in adults. Chest 1996:110:42-7.

55 Idris AH, McDermott MF, Raucci JC, et al. Emergency department treatment of severe asthma: metered-dose inhaler plus holding chamber is equivalent in effectiveness to nebulizer. Chest 1993;103:665-72.

56 Cates CJ, Bara A, Crilly JA, et al. Holding chambers versus nebulisers for betaagonist treatment of acute asthma. Cochrane Database System Rev 2005;(3): 1-58

57 Colacone A, Afilalo M, Wokove N, et al. The comparison of albuterol administered by metered dose inhaler and holding chamber or wet nebuliser in acute asthma. Chest 1993;104:835-41.

58 Rodrigo GJ, Castro-Rodriguez JA. Anticholinergics in the treatment of children and adults with acute asthma: a systematic review with meta-analysis. Thorax 2005;60:740-6

59 Fitzgerald JM, Grunfeld A, Pare PD, et al. The clinical efficacy of combination nebulized anticholinergic and adrenergic bronchodilators vs nebulized adrenergic bronchodilator alone in acute asthma. Chest 1997:111:311-5

60 Ind PW, Dixon CMS, Fuller RW, et al. Anticholinergic blockade of beta-blocker induced bronchoconstriction. Am Rev Respir Dis 1989;139:1390-4.

61 Beasley R, Burgess C, Holt S. Call for worldwide withdrawal of benzalkonium chloride from nebuliser solutions. J Allergy Clin Immunol 2001;107:222-3.

62 Rafferty P, Beasley R, Holgate ST. A comparison of the efficacy of preservative free ipratropium bromide and Atrovent nebuliser solution. Thorax 1988;43:446-50.

63 Beasley R, Fishwick D, Miles JF, et al. Preservatives in nebuliser solutions: risks without benefit. Pharmacotherapy 1998;18:130-9.

64 Hughes R, Goldkorn A, Masoli M, et al. Use of isotonic nebulised magnesium sulphate as an adjuvant to salbutamol in the treatment of severe asthma in adults: randomised placebo-controlled trial. Lancet 2003;361:2114-7.

65 Blitz M, Blitz S, Hughes R, et al. Aerosolized magnesium sulphate for acute asthma: a systematic review. Chest 2005;128:337-44.

66 Rudnitsky GS, Eberlein RS, Schoffstall JM, et al. Comparison of intermittent and continuously nebulized albuterol for treatment of asthma in an urban emergency department. Ann Emerg Med 1993;22:842-6.

67 Douglas JG, Rafferty P, Fergusson RJ, et al. Nebulised salbutamol without oxygen in severe acute asthma: how effective and how safe? Thorax 1985;40:180-3

68 Salmeron S, Brochard L, Mal H, et al. Nebulised versus intravenous albuterol in hypercapnic acute asthma. Am J Respir Crit Care Med 1994;149:1466-70.

69 Travers A, Jones AP, Kelly K, et al. Intravenous $\beta_{2}$-agonists for acute asthma in the emergency department. Cochrane Database Syst Rev 2005;(3):1-45.

70 Swedish Society of Chest Medicine. High dose inhaled versus intravenous salbutamol combined with theophylline in severe acute asthma. Eur Respir J 1990;3:163-70

71 Parameswaran K, Belda J, Rowe BH. Addition of intravenous aminophylline to $\beta_{2}$-agonists in adults with acute asthma. Cochrane Database Syst Rev $2005 ;(3): 1-44$

72 Rowe BH, Bretzlaff JA, Bourdon C, et al. Magnesium sulphate for treatment of acute asthma exacerbations in the ED. Cochrane Database Syst Rev 2002;(1).

73 Rowe BH, Spooner CH, Ducharme FM, et al. Early emergency department treatment of acute asthma with systemic corticosteroids. Cochrane Database Syst Rev 2005;(3): 1-37.

74 Manser R, Reid D, Abramson M. Corticosteroids for acute severe asthma in hospitalised patients. Cochrane Database Syst Rev 2002;(2):1-29.
75 Bowler SD, Mitchell CA, Armstrong JG. Corticosteroids in acute severe asthma: effectiveness of low doses. Thorax 1992;47:584-7.

76 Rowe BH, Keller JL, Oxman AD. Effectiveness of steroid therapy in acute exacerbations of asthma: a meta-analysis. Am J Emerg Med 1992:10:301-10.

77 Harrison BDW, Stokes RC, Hart GJ, et al. Need for intravenous hydrocortisone in addition to oral prednisolone in patients admitted to hospital with severe asthma without ventilatory failure. Lancet 1986;i:181-4.

78 Edmonds ML, Camargo CA Jr, Brenner BE, et al. Inhaled steroids for acute asthma following emergency department discharge. Cochrane Database Syst $\operatorname{Rev} 2005 ;(3): 1-43$.

79 Levy ML, Stevenson C, Maslen T. Comparison of short courses of oral prednisolone and fluticasone propionate in the treatment of adults with acute exacerbations of asthma in primary care. Thorax 1996:51:1087-92.

80 Rodrigo GJ. Comparison of inhaled fluticasone with intravenous hydrocortisone in the treatment of adult acute asthma. Am J Respir Crit Care Med 2005;171:1231-6.

81 Banner AS, Shad RS, Addington WW. Rapid prediction of need for hospitalisation in acute asthma. JAMA 1976;235:1337-8.

82 Tuxen $D$. Intensive care management of severe asthma including assisted ventilation. In: Holgate ST, Boushey HA, Fabbri LM, eds. Difficult asthma. London: Martin Dunitz, 1999:307-31.

83 Corbridge TC, Hall JB. The assessment and management of adults with status asthmaticus. Am J Respir Crit Care Med 1995;151:1296-316.

84 Bucknall CE, Robertson C, Moran F, et al. Differences in hospital asthma management. Lancet 1988;i:748-50.

85 Brophy C, Ahmed B, Bayston S, et al. How long should Atrovent be given in acute asthma? Thorax 1998;53:363-7.

86 Ellul-Micallef $\mathbf{R}$, Johansson SA. Acute dose response studies in bronchial asthma with a new corticosteroid, budesonide. Br J Clin Pharmacol 1983;15:419-22.

87 Beam WR, Weiner DE, Martin RJ. Timing of prednisone and alterations of airways inflammation in nocturnal asthma. Am Rev Respir Dis 1992; 145:1524-30.

88 Webb JR. Dose response of patients to oral corticosteroid treatment during exacerbations of asthma. BMJ 1986;292:1045-7.

89 O'Driscoll BR, Kalra S, Wilson M, et al. Double-blind trial of steroid tapering in acute asthma. Lancet 1993;341:324-7.

90 Hatton MQF, Vathenen AS, Allen MJ, et al. A comparison of 'abruptly stopping' with 'tailing off' oral corticosteroids in acute asthma. Respir Med 1995;89:101-4

91 Graham VAL, Milton AF, Knowles GK, et al. Routine antibiotics in hospital management of acute asthma. Lancet 1982;i:418-20.

92 Sutherland ER, Martin RJ. Is infection important in the pathogenesis and clinical expression of asthma? In: Johnson SL, Holgate ST, eds. Asthma:critical debates. Oxford: Blackwell Science, 2002:69-84.

93 Pearson MG, Ryland I, Harrison BD. National audit of acute severe asthma in adults admitted to hospital. Standards of Care Committee, British Thoracic Society. Qual Health Care 1995;4:24-30.

94 Udwadia ZF, Harrison BD. An attempt to determine the optimal duration of hospital stay following a severe attack of asthma. J R Coll Physicians Lond 1990;24:112-4

95 Bradding P, Rushby I, Scullion J, et al. As-required versus regular nebulized salbutamol for the treatment of acute severe asthma. Eur Respir $J$ 1999; 13:290-4.

96 Rowe BH, Spooner CH, Ducharme FM, et al. Corticosteroids for preventing relapse following acute exacerbations of asthma. Cochrane Database Syst Rev 2005;(3): 1-22.

97 Crompton GK, Grant IWB. Edinburgh emergency asthma admission service. BMJ 1975:4:680-2.

98 Emond SD, Woodruff PG, Lee EY, et al. Effect of an emergency department asthma program on acute asthma care. Ann Emerg Med 1999;34:321-5.

99 Wrenn K, Rodewald L, Lumb E, et al. The use of structured, complaint-specific patient encounter forms in the emergency department. Ann Emerg Med 1993;22:55-62

100 Town I, Kwong T, Holst $P$, et al. Use of a management plan for treating asthma in an emergency department. Thorax 1990;45:702-6.

101 McFadden ER Jr, Elsanadi N, Dixon L, et al. Protocol therapy for acute asthma: therapeutic benefits and cost savings. Am J Med 1995;99:651-61.

102 Goldberg R, Chan L, Haley P, et al. Critical pathway for the emergency department management of acute asthma: effect of resource utilization. Ann Emerg Med 1998;31:562-7.

103 Robinson SM, Harrison BD, Lambert MA. Effect of a preprinted form on the management of acute asthma in an accident and emergency department. $J$ Accid Emerg Med 1996;13:93-7.

104 Pinnock H, Johnson A, Young P, et al. Are doctors still failing to assess and treat asthma attacks? An audit of the management of acute attacks in a health district. Respir Med 1999;93:397-401.

105 McFadden ER Jr, Hejal R. Asthma. Lancet 1995;345:1215-20. 